\title{
RADIATION OF HEAT FROM THE HUMAN BODY: A STATEMENT RELATIVE TO THE CRITIQUE OF J. D. HARDY
}

\author{
By PROFESSOR H. BOHNENKAMP \\ (From Medizinische und Nervenklinik, University of Giessen, Giessen, Germany)
}

(Received for publication August 15, 1934)

Dr. Hardy ${ }^{1}$ has made careful recalculations of our experiments on the radiation of the human body. He has found errors in our work and has most kindly called our attention to them. After recalculation I wish to make the following statement:

There is, as a matter of fact, an error which slipped in twice, in that the graphic average value should have been multiplied by the integrationinterval. This mistake obviously escaped notice because it was almost compensated by a second error so that the final results came out on the whole approximately correct. We cannot at the present time prove with the old radiometer whether or not these deviations were caused entirely by the difference in wave lengths of the emission of the Hefner lamp used for the calibration and the wave lengths of radiation from the human subjects. The instrument in the meantime has been greatly changed by many alterations in construction necessitated by further experiments. It would be preferable to repeat the entire measurements with a new calibration. In the meantime this has been done by Dr. Hardy. It is therefore of particular importance to us and fortunate for the general development of this field of investigation that the measurements of Dr. Hardy which have avoided our errors lead to the same end results.

In spite of the uncertainty implied by these mistakes we hold fast to our position on the basis of thorough considerations, supported as they are by the results of Dr. Hardy. We believe that our theoretical procedure as well as the method chosen for experimental proof is correct. In this conclusion we have been confirmed by our new investigations of this problem carried on in the last few years.

1 Hardy, James D., The radiation of heat from the human body. I. An instrument for measuring the radiation and surface temperature of the skin. J. Clin. Invest., 1934, 13, 593. See p. 602. 